\title{
Lactate Dehydrogenase Isoenzyme 1 Measurement
}

National Cancer Institute

\section{Source}

National Cancer Institute. Lactate Dehydrogenase Isoenzyme 1 Measurement. NCI

Thesaurus. Code C74887.

The determination of the lactate dehydrogenase isoenzyme 1 present in a sample. 